\title{
Cardiac surgery for the forgotten millions: The way forward. Cardiac Surgery Intersociety Alliance (CSIA) Site Selection Criteria
}

\author{
Percy Boateng, ${ }^{\mathrm{a}}$ R. Morton Bolman III, ${ }^{\mathrm{b}, \mathrm{c}}$ and Peter Zilla, ${ }^{\mathrm{d}}$ on behalf of CSIA
}

\footnotetext{
From the ${ }^{a}$ Department of Cardiovascular Surgery, Icahn School of Medicine, Mount Sinai (ISMMS) Medical Center, New York, NY; ${ }^{b}$ University of Colorado Denver, Denver, Colo; ${ }^{c}$ University of Colorado, Anschutz Medical Campus, Aurora, Colo; and ${ }^{\mathrm{d} C h r i s t i a n}$ Barnard Department for Cardiothoracic Surgery, University of Cape Town and Groote Schuur Hospital, Cape Town, South Africa.

Disclosures: Authors have nothing to disclose with regard to commercial support.

This article has been co-published with permission in The Journal of Thoracic and Cardiovascular Surgery, European Journal of Cardio-Thoracic Surgery, The Annals of Thoracic Surgery, and the Asian Cardiovascular and Thoracic Annals.

Cite this article as: Boateng P, Bolman RM III, Zilla P, on behalf of CSIA. Cardiac surgery for the forgotten millions: the way forward. Cardiac Surgery Intersociety Alliance (CSIA) Site Selection Criteria. J Thorac Cardiovasc Surg. 2019;158:818-9.

Address for reprints: Percy Boateng, Department of Cardiovascular Surgery, Icahn School of Medicine at Mount Sinai (ISMMS) Medical Center, 1 Gustave L. Levy Pl, New York, NY 10029 (E-mail: percy.boateng@ mountsinai.org).

J Thorac Cardiovasc Surg 2019;158:818-9

$0022-5223 / \$ 36.00$

(C) 2019. The European Association for Cardio-Thoracic Surgery, The Society of Thoracic Surgeons, The American Association for Thoracic Surgery and Sage Publications Ltd. Published by Oxford University Press/Elsevier Inc./Sage Publishing. All rights reserved.

https://doi.org/10.1016/j.jtcvs.2019.06.030
}

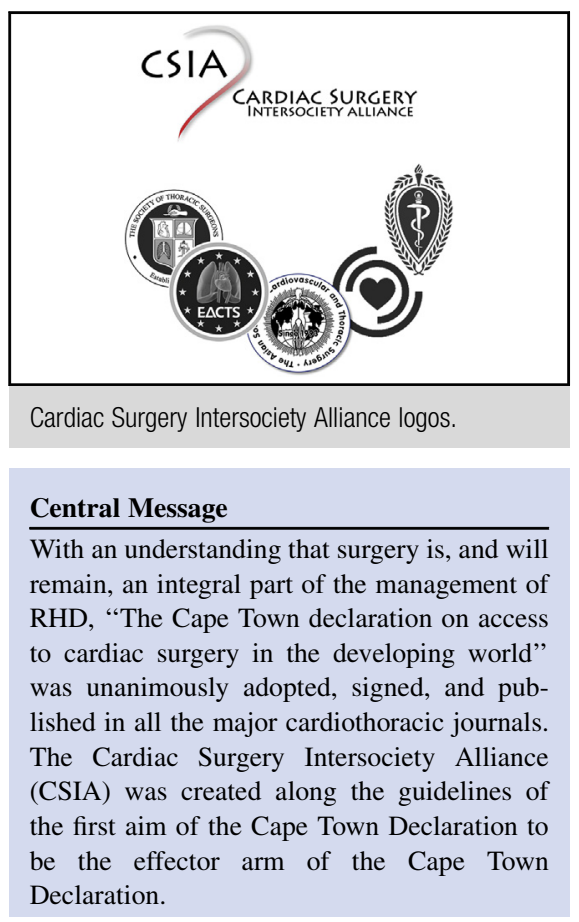

Society for Cardiovascular and Thoracic Surgery), the World Heart Federation, and an industry representative. The CSIA is charged with evaluating, endorsing, mentoring, and monitoring potential sites in LMIC to increase access to cardiac surgery, as well as training of providers at these sites.

To achieve this goal, a list of criteria for program selection by the CSIA was created and is included in this publication-see Announcement at the end of the issue. This list has been reviewed and ratified by the leadership of all of the societies whose members make up the CSIA. The tenets of the document embody the central message of the Cape Town Declaration. The criteria list was created with the goal of being collaborative with the sites while ensuring commitment, engagement, transparency, and sustainability from the sites that are chosen. Any site chosen will ideally have the 5 pillars of CSIA supported projects, which are The Driver (Champion), The Local Guarantor, The Sponsor, The Training Site, and The Academic Partner.

The initial plan is to select $2-3$ pilot sites to initiate the project. Once success and feasibility have been demonstrated, CSIA will expand this project to additional sites. The CSIA is looking for sites that are passionate and 
dedicated and determined to establish an enduring successful partnership. The CSIA will be accepting applications through September 10, 2019. All programs are encouraged to apply. If not selected for the initial pilot site, all applications will be entered into a database for consideration at a future date.

See Announcement at the end of the issue.

\section{References}

1. Zilla P, Yacoub M, Zühlke L, Beyersdorf F, Sliwa K, Khubulava G, et al. Global unmet needs in cardiac surgery. Global Heart. 2018;13:293-303.

2. Mayosi B, Robertson K, Volmink J, Adebo W, Akinyore K, Amoah A, et al. The Drakensberg declaration on the control of rheumatic fever and rheumatic heart disease in Africa. S Afr Med J. 2006;96:246.

3. Zilla P, Bolman RM, Yacoub MH, Beyersdorf F, Sliwa K, Zühlke L, et al. The Cape Town declaration on access to cardiac surgery in the developing world. Eur J Cardiothorac Surg. 2018;54:407-10. 